\title{
Synthesis of 1-[bis(trifluoromethyl)phosphine]-1'- oxazolinylferrocene ligands and their application in regio- and enantioselective Pd-catalyzed allylic alkylation of monosubstituted allyl substrates
}

\author{
Zeng-Wei Lai ${ }^{1,2}$, Rong-Fei Yang ${ }^{3}$, Ke-Yin Ye ${ }^{1}$, Hongbin Sun ${ }^{* 2}$ \\ and Shu-Li You*1
}

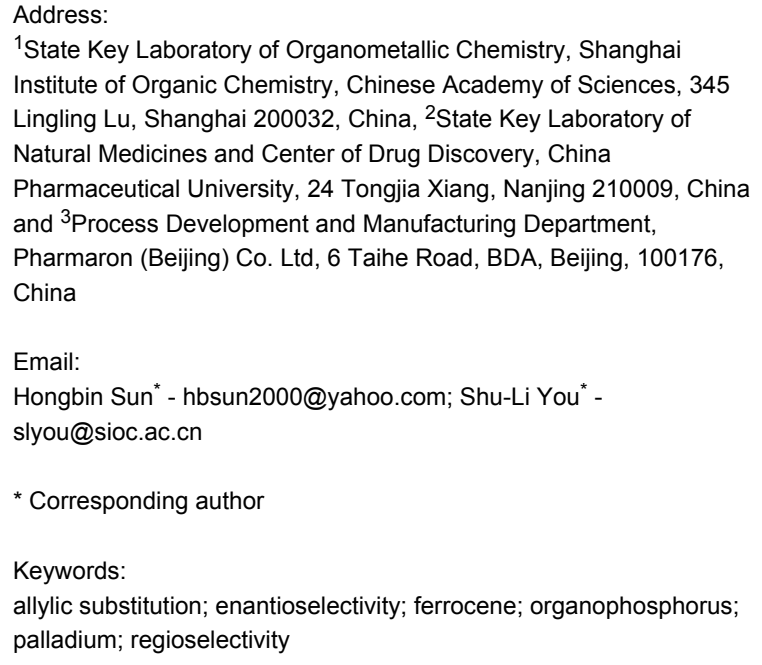

${ }^{1}$ State Key Laboratory of Organometallic Chemistry, Shanghai Institute of Organic Chemistry, Chinese Academy of Sciences, 345 Lingling Lu, Shanghai 200032, China, ${ }^{2}$ State Key Laboratory of Natural Medicines and Center of Drug Discovery, China Pharmaceutical University, 24 Tongjia Xiang, Nanjing 210009, China and ${ }^{3}$ Process Development and Manufacturing Department, Pharmaron (Beijing) Co. Ltd, 6 Taihe Road, BDA, Beijing, 100176, China

Email:

Hongbin Sun* - hbsun2000@yahoo.com; Shu-Li You* -

slyou@sioc.ac.cn

* Corresponding author

Keywords:

allylic substitution; enantioselectivity; ferrocene; organophosphorus; palladium; regioselectivity

Beilstein J. Org. Chem. 2014, 10, 1261-1266.

doi:10.3762/bjoc. 10.126

Received: 05 January 2014

Accepted: 05 May 2014

Published: 30 May 2014

This article is part of the Thematic Series "Organophosphorus chemistry".

Guest Editor: P. R. Hanson

(C) 2014 Lai et al; licensee Beilstein-Institut.

License and terms: see end of document.

\begin{abstract}
A class of novel, easily accessible and air-stable 1-[bis(trifluoromethyl)phosphine]-1'-oxazolinylferrocene ligands has been synthesized from ferrocene. It became apparent that these ligands can be used in the regio- and enantioselective Pd-catalyzed allylic alkylation of monosubstituted allyl substrates in a highly efficient manner. Excellent regio- and enantioselectivity could be obtained for a wide range of substrates.
\end{abstract}

\section{Introduction}

The palladium-catalyzed asymmetric allylic alkylation (AAA) reaction is now becoming an efficient method for the construction of carbon-carbon bonds [1-5]. Despite extensive investigation and noteworthy advances in this field, several challenges remain to be solved. For instance, with monosubstituted allyl substrates, the palladium-catalyzed allylic substitution reaction prefers to give linear products rather than the branched ones [6-9] (Scheme 1). Accordingly, the regio- and enantioselective allylic substitution reaction of monosubstituted allylic substrates to preferably obtain the branched products is one of the contin- 
uing challenges. To our knowledge, there are several cases in which high levels of both regio- and enantioselectivity have been realized by introducing special ligands [10-34] (Figure 1). Hayashi and coworkers reported a sterically bulky chiral monophosphine ligand (MeO-MOP) could be used for the Pd-catalyzed alkylation of branched monosubstituted allyl acetate favoring the branched products. However, linear products were favored when the linear allyl substrates were employed [23,24]. The chiral oxazoline-phosphite ligands introduced by Pfaltz and coworkers proved to be highly efficient for regio- and enantiocontrol in the Pd-catalyzed allylic alkylation reaction. Excellent results were obtained for the bulky and electron-rich aryl allyl substrates [25-27]. In 2001, Dai, Hou and their coworkers synthesized a new class of 1,1'ferrocene-based $P, N$-ligands, namely SiocPhox. The application of these SiocPhox ligands in the Pd-catalyzed allylic substitution led to excellent regio- and enantioselectivities for a wide range of substrates in both allylic alkylation and amination reactions despite of the electronic properties of the allylic substrates [28-33]. Recently, Shen and co-workers reported an elegant synthesis of bis(perfluoroalkyl)phosphine-oxazoline ligands where small but strongly electron-withdrawing substituents were introduced at the phosphorus [34]. 1,2-Ferrocene based $P, N$-ligands were synthesized and gave excellent regio- and enantioselectivities in the Pd-catalyzed allylic alkylation reactions of monosubstituted allylic substrates. Inspired by these pioneering studies above and as our continuing interests in the transition metal-catalyzed asymmetric allylic alkylation reaction [35-38], we envisaged that the 1-[bis(trifluoromethyl)phosphine]-1'-oxazolinylferrocene ligands, a straightforward combination of the features of SiocPhox and Shen's ligand, should be highly efficient for the Pd-catalyzed allylic alkylation reactions of monosubstituted allyl substrates. Herein, we report the synthesis of 1-[bis(trifluoromethyl)phosphine]-1'-oxazolinylferrocene ligands and their application in Pd-catalyzed allylic alkylation reactions of monosubstituted allyl substrates with excellent regio- and enantioselectivity.

\section{Results and Discussion}

As depicted in Scheme 2, ligands L1a-L1d were synthesized from known compounds $\mathbf{3}$, which were obtained from ferrocene in three steps according to the reported procedures [39-41]. The commercially available ferrocene was dilithiated with $n$-BuLi and then quenched with dibromoterafluoroethane to give dibromoferrocence 1 . Treatment of $\mathbf{1}$ with $n$-BuLi at $-20{ }^{\circ} \mathrm{C}$ followed by trapping with $\mathrm{CO}_{2}$ afforded compound 2 . Treatment of compound 2 with $(\mathrm{COCl})_{2}$ and then chiral amino alcohols yielded the amide intermediates which were transformed to their corresponding 1-bromo-1'-oxazolinylferrocenes 3. Eventually, lithium-bromide exchange of 3 with $n$-BuLi at $-78{ }^{\circ} \mathrm{C}$, followed by quenching with $\mathrm{P}(\mathrm{OPh})_{3}$, provided the phosphonite intermediates which were used without further purification. Subsequently, trifluoromethylation provided the ligands L1a-d in moderate yields, upon treatment with Ruppert's reagent $\left(\mathrm{TMSCF}_{3}\right)$ and $\mathrm{CsF}$ [42-45]. Notably, ligands L1a-d are moisture and air-stable, and their NMR spectra show no change even after being stored over six months under ambient atmosphere.

To test the suitability of these 1-[bis(trifluoromethyl)phosphine]-1'-oxazolinylferrocene ligands in Pd-catalyzed allylic alkylation reactions, we began our study by choosing methyl cinnamyl carbonate and dimethyl malonate as the model<smiles>COc1ccc2ccccc2c1-c1c(-c2ccccc2)ccc2ccccc12</smiles>

(R)-MeO-MOP<smiles>CC(C)(Op1oc2ccc3ccccc3c2c2c(ccc3ccccc32)o1)C1=N[C@H](C(C)(C)C)CO1</smiles>

Pfaltz's ligand

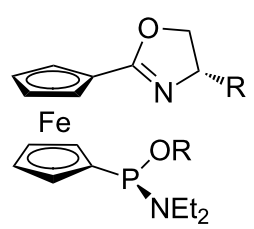

SiocPhox

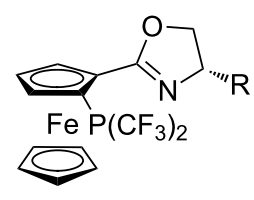

Shen's ligand

Figure 1: Representative ligands developed for the regio- and enantioselective Pd-catalyzed allylic alkylation.

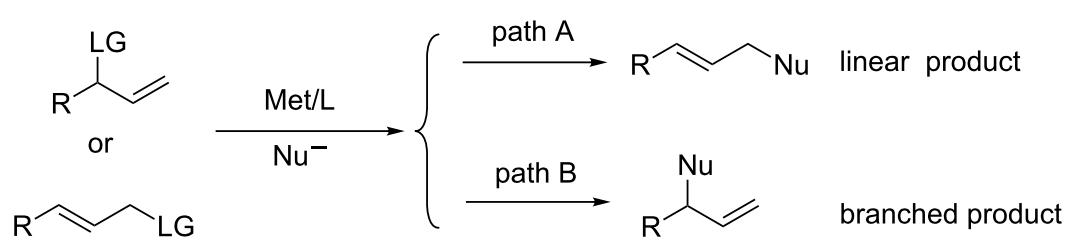




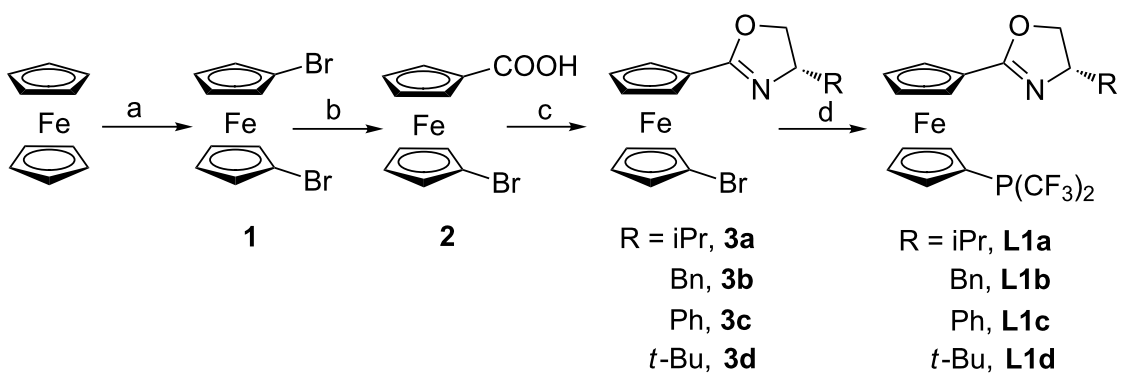

Scheme 2: Preparation of 1-[bis(trifluoromethyl)phosphine]-1'-oxazolinylferrocene ligands. Reagents and conditions: (a) (i) $n$-BuLi, TMEDA, Et ${ }_{2} \mathrm{O}$, $r$; (ii) $\left(\mathrm{BrCF}_{2}\right)_{2},-78^{\circ} \mathrm{C}$. (b) $n$-BuLi, $\mathrm{CO}_{2}, \mathrm{THF},-20^{\circ} \mathrm{C}$. (c) (i) $(\mathrm{COCl})_{2}, \mathrm{DCM}$, rt; then TEA, amino alcohol, $\mathrm{DCM}, \mathrm{rt}$; (ii) $\mathrm{Ph}_{3} \mathrm{P}, \mathrm{CCl}_{4}, \mathrm{TEA}, \mathrm{CH}_{3} \mathrm{CN}, \mathrm{rt}$. (d) (i) $n$-BuLi, TMEDA, $\mathrm{P}(\mathrm{OPh})_{3}, \mathrm{Et}_{2} \mathrm{O},-78^{\circ} \mathrm{C}$; (ii) $\mathrm{TMSCF}_{3}, \mathrm{CsF}, \mathrm{Et}_{2} \mathrm{O}$, rt.

substrates, along with the catalysts derived from $\mathrm{Pd}_{2}(\mathrm{dba})_{3}$ and ligands 1a-d. The results are summarized in Table 1. Ligands L1a-d were screened in the reaction using bis(trimethylsilyl)acetamide (BSA) as the base and LiOAc as the additive. The results suggested that ligands $\mathbf{L 1 a}-\mathbf{d}$ were effective for this reaction with full conversion and high selectivities (entries 1-4, Table 1). The catalyst derived from L1d gave the highest selectivities [b/1 (branched/linear): 95/5, 82\% ee; entry 4, Table 1]. With ligand L1d, different reaction parameters including the Pd precursor and solvent were further optimized. The utilization of $\left[\mathrm{Pd}\left(\mathrm{C}_{3} \mathrm{H}_{5}\right) \mathrm{Cl}\right]_{2}$ as Pd precursor or DCM as solvent resulted in slightly lower selectivities (entries 5-6, Table 1). Further screening of the additives revealed that $\mathrm{NaOAc}$ was the optimal one (b/1: 97/3, 85\% ee, entry 7 , Table 1$)$. Running the reaction at $0{ }^{\circ} \mathrm{C}$ resulted in an increased enantioselectivity (b/1: 96/4, $88 \%$ ee, entry 9 , Table 1 ). When the reaction was run at $-30{ }^{\circ} \mathrm{C}$, only a trace amount of product was formed. As for the leaving groups of allyl substrates, the cinnamyl acetate could also be tolerated to give a similar level of regio- and enantioselectivity (entry 11, Table 1). The absolute configuration of the product was assigned as $(S)$ by comparing the sign of the optical rotation with that reported in literature [28].

Under the optimized reaction conditions ( $2 \mathrm{~mol} \%$ of $\mathrm{Pd}_{2}(\mathrm{dba})_{3}$, $4 \mathrm{~mol} \%$ of L1d, $300 \mathrm{~mol} \%$ of $\mathrm{CH}_{2}(\mathrm{COOMe})_{2}, 300 \mathrm{~mol} \%$ of BSA and $3 \mathrm{~mol} \%$ of $\mathrm{NaOAc}$ in DCE at $0{ }^{\circ} \mathrm{C}$; entry 9, Table 1), the substrate scope was examined to test the generality of the reaction (Table 2). We first compared the reaction of branched

Table 1: Evaluation of the ligands and optimization of the reaction conditions. ${ }^{a}$

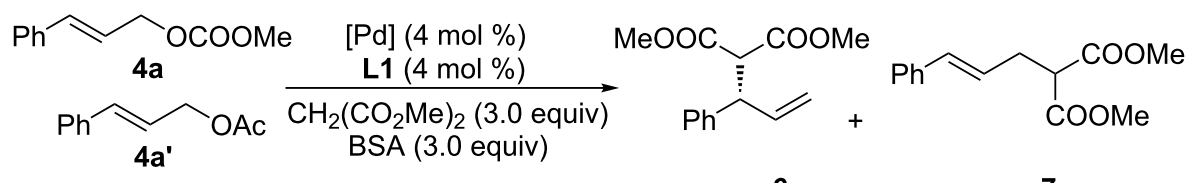

$6 a$

$7 \mathbf{a}$

\begin{tabular}{|c|c|c|c|c|c|c|c|c|c|}
\hline entry & 4 or $4 a^{\prime}$ & {$[\mathrm{Pd}]$} & L1 & Additive & Solvent & $T\left({ }^{\circ} \mathrm{C}\right)$ & Yield $(\%)^{b}$ & $6 a / 7 a^{c}$ & ee $(\%)^{d}$ \\
\hline 1 & $4 a$ & $\mathrm{Pd}_{2}(\mathrm{dba})_{3}$ & L1a & LiOAC & DCE & $\mathrm{rt}$ & 95 & $84 / 16$ & 68 \\
\hline 2 & $4 a$ & $\mathrm{Pd}_{2}(\mathrm{dba})_{3}$ & L1b & LiOAc & DCE & $\mathrm{rt}$ & 96 & $93 / 7$ & 68 \\
\hline 3 & $4 a$ & $\mathrm{Pd}_{2}(\mathrm{dba})_{3}$ & L1c & LiOAC & DCE & $\mathrm{rt}$ & 91 & $85 / 15$ & 80 \\
\hline 4 & $4 a$ & $\mathrm{Pd}_{2}(\mathrm{dba})_{3}$ & L1d & LiOAc & DCE & $\mathrm{rt}$ & 95 & $95 / 5$ & 82 \\
\hline 5 & $4 a$ & {$\left[\mathrm{Pd}\left(\mathrm{C}_{3} \mathrm{H}_{5}\right) \mathrm{Cl}\right]_{2}$} & L1d & LiOAc & DCE & $\mathrm{rt}$ & 93 & $90 / 10$ & 76 \\
\hline 6 & $4 a$ & $\mathrm{Pd}_{2}(\mathrm{dba})_{3}$ & L1d & LiOAC & $\mathrm{DCM}$ & $\mathrm{rt}$ & 91 & $83 / 17$ & 76 \\
\hline 7 & $4 a$ & $\mathrm{Pd}_{2}(\mathrm{dba})_{3}$ & L1d & $\mathrm{NaOAc}$ & DCE & $\mathrm{rt}$ & 90 & $97 / 3$ & 85 \\
\hline 8 & $4 a$ & $\mathrm{Pd}_{2}(\mathrm{dba})_{3}$ & L1d & KOAc & DCE & $\mathrm{rt}$ & 91 & $91 / 9$ & 82 \\
\hline 9 & $4 a$ & $\mathrm{Pd}_{2}(\mathrm{dba})_{3}$ & L1d & $\mathrm{NaOAc}$ & DCE & 0 & 95 & $96 / 4$ & 88 \\
\hline $10^{e}$ & $4 a$ & $\mathrm{Pd}_{2}(\mathrm{dba})_{3}$ & L1d & $\mathrm{NaOAc}$ & DCE & -30 & trace & nd & nd \\
\hline $11^{e}$ & $4 a^{\prime}$ & $\mathrm{Pd}_{2}(\mathrm{dba})_{3}$ & L1d & $\mathrm{NaOAc}$ & DCE & $\mathrm{rt}$ & 80 & $95 / 5$ & 87 \\
\hline
\end{tabular}

aReagents and conditions: $2.0 \mathrm{~mol} \% \mathrm{Pd}_{2}(\mathrm{dba})_{3}, 4.0 \mathrm{~mol} \%$ ligand, $0.2 \mathrm{mmol}$ allyl substrate, $0.6 \mathrm{mmol}$ dimethyl malonate, $0.6 \mathrm{mmol} \mathrm{BSA}, 3.0 \mathrm{~mol} \%$ additive, solvent $(2 \mathrm{~mL})$. ${ }^{b}$ Isolated yield after $12 \mathrm{~h}$. C Determined by ${ }^{1} \mathrm{H}$ NMR of the crude reaction mixture. ${ }^{\mathrm{d} D e t e r m i n e d ~ b y ~ H P L C . ~}{ }^{\mathrm{e}} \mathrm{Reaction}$ for $24 \mathrm{~h}$. 
Table 2: Regio- and enantioselective allylic alkylation of monosubstituted allyl substrates. ${ }^{\text {a }}$

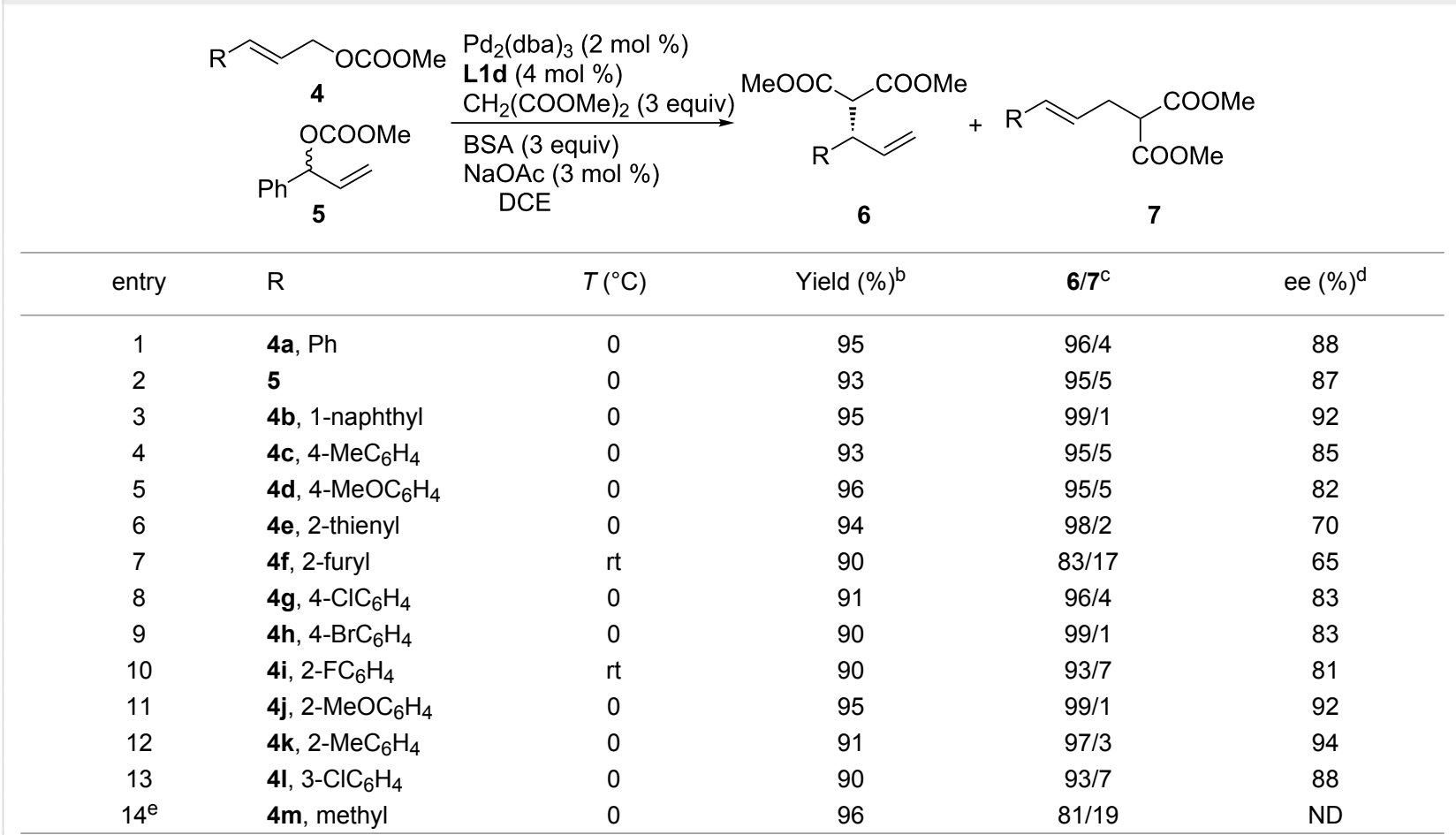

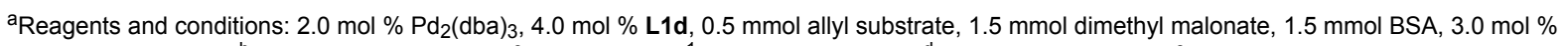
$\mathrm{NaOAc}, \mathrm{DCE}(5 \mathrm{~mL})$. b/solated yield after $12 \mathrm{~h}$. ${ }^{c}$ Determined by ${ }^{1} \mathrm{H}$ NMR of the crude. dDetermined by $\mathrm{HPLC}$. ${ }^{e}\left[\mathrm{Pd}\left(\mathrm{C}_{3} \mathrm{H}_{5}\right) \mathrm{Cl}\right]_{2}$ as the Pd precursor.

substrate 5 with the linear substrate 4a. Nearly identical results were obtained indicating that the reaction proceeds via the formation of the same Pd- $\pi$-allyl intermediate. Substrates bearing either an electron-donating group or electron-withdrawing group on the aromatic ring of the aryl allyl carbonates all proceeded smoothly in full conversion within $12 \mathrm{~h}$. In all cases, the reactions gave excellent regioselectivity favoring the formation of the branched products in good to excellent enantioselectivity (b/1: 93/7-99/1, 81-94\% ee). It is known that the regioselectivity could be strongly influenced by electronic properties of the allyl substrates and the formation of branched products was dramatically reduced for substrates bearing electronwithdrawing groups [21]. Fortunately, with our catalytic system, substrates bearing electron-withdrawing groups were well tolerated with excellent regioselectivity and preferred formation of the branched products (b/1: 93/7-99/1, entries 8-10, and 13, Table 2). Reactions of sterically hindered 1-naphthyl allyl carbonate, 2-MeO and 2-Me-substituted cinnamyl carbonates occurred smoothly to give excellent regio- and enantioselectivity (b/1: up to $99 / 1$, up to $94 \%$ ee, entries $3,11,12$, Table 2). In addition, heteroaryl allyl carbonates $\mathbf{4 e}$ and $\mathbf{4 f}$ also gave good regioselectivity with slightly lower enantioselectivity (entries 6 and 7, Table 2). Good regioselectivity (b/1: $81 / 19$ ) was obtained with 2-buten-3-yl carbonate as a substrate (entry 14 , Table 2).
We conducted some control experiments to probe the effect of the bis(trifluoromethyl) group in the ligands (Scheme 3). With ferrocence-based biphenyl phosphine-oxazoline $\mathbf{L} 2$ as the ligand, the Pd-catalyzed allylic alkylation of cinnamyl carbonate with dimethyl malonate afforded the linear product as the major product (b/1: 40/60). Whereas the corresponding ligand $\mathbf{L 1 d}$ with two $\mathrm{CF}_{3}$ groups (instead of two phenyl groups) at the $\mathrm{P}$ atom improved the regioselectivity significantly $(\mathrm{b} / \mathrm{l}$ : 96/4). A preliminary explanation was described in Figure 2. In addition to the effect of different metals, there are at least two additional factors controlling the regioselectivity of the allylic alkylation reaction. The steric factor favors path a since the terminal allylic carbon is less hindered. In contrast, when the $\mathrm{R}$ group has the ability to stabilize the carbocation, the electronic factor would favor the formation of the branched product (path b). The phosphorus atom has a stronger trans effect comparing with the oxazoline nitrogen, indicating that the carbon trans to phosphorus atom bears more electropositivity [46]. This fact may be responsible for the preferred placement of the substituted allylic carbon in the trans position to the phosphorus atom to better stabilize the electropositivity of the carbon. When the nucleophile attacks the more electropositive substituted allylic carbon terminus, a branched product will be formed. The introduction of the $\mathrm{CF}_{3}$ group on the phosphorus atom further increases the trans influence of the $\mathrm{P}\left(\mathrm{CF}_{3}\right)_{2}$ moiety and 


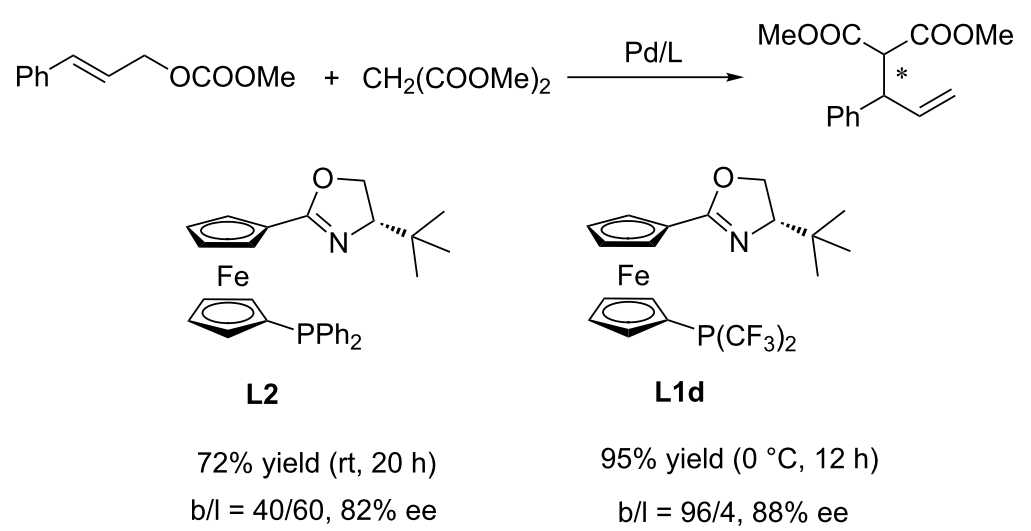

Scheme 3: Comparison of the effect of ligands in the reaction.

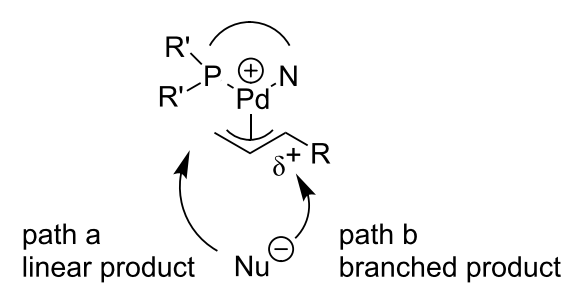

Figure 2: Preliminary explanation of the regioselectivity.

enhances the electronic factor, providing a better branchedproduct selectivity. Further experimental studies and computational investigation are still needed to confirm this hypothesis.

\section{Conclusion}

In summary, we have synthesized a class of novel and efficient bis(trifluoromethyl)phosphine-oxazolines as $\pi$-acceptor ligands which have shown good to excellent regio- and enantioselectivity for the Pd-catalyzed asymmetric allylic alkylation reaction of monosubstituted allyl carbonates. Further studies on the synthesis of 1-[bis(perfluoroalkyl)phosphine]-1'-oxazolinylferrocene ligands and their applications in asymmetric catalysis are ongoing in our lab.

\section{Supporting Information}

\section{Supporting Information File 1}

Experimental, characterization data and spectra.

[http://www.beilstein-journals.org/bjoc/content/ supplementary/1860-5397-10-126-S1.pdf]

\section{Acknowledgements}

We thank the National Basic Research Program of China (973 Program 2010CB833300), the National Natural Science Foun- dation of China (21025209, 21121062, 21332009), and the Chinese Academy of Sciences for generous financial support.

\section{References}

1. Trost, B. M.; Van Vranken, D. L. Chem. Rev. 1996, 96, 395. doi:10.1021/cr9409804

2. Pfaltz, A.; Lautens, M. In Comprehensive Asymmetric Catalysis; Pfaltz, A.; Yamamoto, H., Eds.; Springer: New York, 1999; Vol. 2, pp $833 \mathrm{ff}$.

3. Trost, B. M.; Crawley, M. L. Chem. Rev. 2003, 103, 2921. doi:10.1021/cr020027w

4. Lu, Z.; Ma, S. Angew. Chem., Int. Ed. 2008, 47, 258. doi:10.1002/anie.200605113

5. Förster, S.; Helmchen, G.; Kazmaier, U. In Catalytic Asymmetric Synthesis, 3rd ed.; Ojima, I., Ed.; Wiley: Hoboken, 2010; pp 497 ff.

6. Hayashi, T.; Kishi, K.; Yamamoto, A.; Ito, Y. Tetrahedron Lett. 1990, 31, 1743. doi:10.1016/S0040-4039(00)88870-X

7. Trost, B. M.; Krische, M. J.; Radinov, R.; Zanoni, G. J. Am. Chem. Soc. 1996, 118, 6297. doi:10.1021/ja960649x

8. Trost, B. M.; Toste, F. D. J. Am. Chem. Soc. 1998, 120, 9074 doi:10.1021/ja981142k

9. Trost, B. M.; Tsui, H.-C.; Toste, F. D. J. Am. Chem. Soc. 2000, 122, 3534. doi:10.1021/ja994326n

10. Vyskočil, Š.; Smrčina, M.; Hanuš, V.; Polášek, M.; Kočovský, P. J. Org. Chem. 1998, 63, 7738. doi:10.1021/jo980757x

11. Tenaglia, A.; Heumann, A. Angew. Chem., Int. Ed. 1999, 38, 2180. doi:10.1002/(SICI)1521-3773(19990802)38:15<2180::AID-ANIE2180>3 .0.CO;2-A

12. Nakano, H.; Okuyama, Y.; Hongo, H. Tetrahedron Lett. 2000, 41, 4615 doi:10.1016/S0040-4039(00)00674-2

13. Boele, M. D. K.; Kamer, P. C. J.; Lutz, M.; Spek, A. L.; de Vries, J. G.; van Leeuwen, P. W. N. M.; van Strijdonck, G. P. F. Chem.-Eur. J. 2004, 10, 6232. doi:10.1002/chem.200400154

14. Pàmies, O.; Diéguez, M.; Claver, C. J. Am. Chem. Soc. 2005, 127, 3646. doi:10.1021/ja0425738

15. Diéguez, M.; Pàmies, O.; Claver, C. Adv. Synth. Catal. 2005, 347, 1257. doi:10.1002/adsc.200505013

16. Diéguez, M.; Pàmies, O.; Claver, C. J. Organomet. Chem. 2006, 691, 2257. doi:10.1016/j.jorganchem.2005.11.024 
17. Raluy, E.; Diéguez, M.; Pàmies, O. J. Org. Chem. 2007, 72, 2842. doi:10.1021/jo062311j

18. Goldfuss, B.; Löschmann, T.; Kop-Weiershausen, T.; Neudörfl, J.; Rominger, F. Beilstein J. Org. Chem. 2006, 2, No. 7. doi:10.1186/1860-5397-2-7

19. Popa, D.; Puigjaner, C.; Gómez, M.; Benet-Buchholz, J.; Vidal-Ferran, A.; Pericàs, M. A. Adv. Synth. Catal. 2007, 349, 2265. doi:10.1002/adsc.200600599

20. Cheung, H. Y.; Yu, W.-Y.; Au-Yeung, T. T. L.; Zhou, Z.; Chan, A. S. C. Adv. Synth. Catal. 2009, 351, 1412. doi:10.1002/adsc.200900086

21. Rosas-Hernández, A.; Vargas-Malvaez, E.; Martin, E.; Crespi, L.; Bayón, J. C. J. Mol. Catal. A 2010, 328, 68. doi:10.1016/j.molcata.2010.06.001

22. Gual, A.; Castillón, S.; Pàmies, O.; Diéguez, M.; Claver, C. Dalton Trans. 2011, 40, 2852. doi:10.1039/c0dt01067g

23. Hayashi, T.; Kawatsura, M.; Uozumi, Y. Chem. Commun. 1997, 561. doi:10.1039/a700045f

24. Hayashi, T.; Kawatsura, M.; Uozumi, Y. J. Am. Chem. Soc. 1998, 120, 1681. doi:10.1021/ja973150r

25. Prétôt, R.; Pfaltz, A. Angew. Chem., Int. Ed. 1998, 37, 323 doi:10.1002/(SICI)1521-3773(19980216)37:3<323::AID-ANIE323>3.0. CO;2-T

26. Hilgraf, R.; Pfaltz, A. Synlett 1999, 1814. doi:10.1055/s-1999-2939

27. Hilgraf, R.; Pfaltz, A. Adv. Synth. Catal. 2005, 347, 61. doi:10.1002/adsc.200404168

28. You, S.-L.; Zhu, X.-Z.; Luo, Y.-M.; Hou, X.-L.; Dai, L.-X. J. Am. Chem. Soc. 2001, 123, 7471. doi:10.1021/ja016121w

29. Zheng, W.-H.; Sun, N.; Hou, X.-L. Org. Lett. 2005, 7, 5151. doi:10.1021/ol051882f

30. Zheng, W.-H.; Zheng, B.-H.; Zhang, Y.; Hou, X.-L. J. Am. Chem. Soc. 2007, 129, 7718. doi:10.1021/ja071098I

31. Fang, P.; Ding, C.-H.; Hou, X.-L.; Dai, L.-X. Tetrahedron: Asymmetry 2010, 21, 1176. doi:10.1016/j.tetasy.2010.03.045

32. Chen, J.-P.; Ding, C.-H.; Liu, W.; Hou, X.-L.; Dai, L.-X. J. Am. Chem. Soc. 2010, 132, 15493. doi:10.1021/ja106703y

33. Yang, X.-F.; Yu, W.-H.; Ding, C.-H.; Ding, Q.-P.; Wan, S.-L.; Hou, X.-L.; Dai, L.-X.; Wang, P.-J. J. Org. Chem. 2013, 78, 6503. doi:10.1021/j0400663d

34. Hu, Z.; Li, Y.; Liu, K.; Shen, Q. J. Org. Chem. 2012, 77, 7957. doi:10.1021/jo3011717

35. Liu, W.-B.; Zheng, C.; Zhuo, C.-X.; Dai, L.-X.; You, S.-L. J. Am. Chem. Soc. 2012, 134, 4812. doi:10.1021/ja210923k

36. Liu, W.-B.; Zhang, X.; Dai, L.-X.; You, S.-L. Angew. Chem., Int. Ed. 2012, 51, 5183. doi:10.1002/anie.201200649

37. Ye, K.-Y.; Dai, L.-X.; You, S.-L. Org. Biomol. Chem. 2012, 10, 5932. doi:10.1039/c2ob00036a

38. Ye, K.-Y.; Zhao, Z.-A.; Lai, Z.-W.; Dai, L.-X.; You, S.-L. Synthesis 2013, 45, 2109. doi:10.1055/s-0033-1339187

39. Dong, T.-Y.; Lai, L.-L. J. Organomet. Chem. 1996, 509, 131. doi:10.1016/0022-328X(95)05813-5

40. Chesney, A.; Bryce, M. R.; Chubb, R. W. J.; Batsanov, A. S.; Howard, J. A. K. Synthesis 1998, 413. doi:10.1055/s-1998-2051

41. Park, J.; Quan, Z.; Lee, S.; Ahn, K. H.; Cho, C.-W. J. Organomet. Chem. 1999, 584, 140. doi:10.1016/S0022-328X(99)00125-4

42. Tworowska, I.; Dabkowski, W.; Michalski, J. Angew. Chem., Int. Ed. 2001, 40, 2898.

doi:10.1002/1521-3773(20010803)40:15<2898::AID-ANIE2898>3.0.CO ;2-I
43. Murphy-Jolly, M. B.; Lewis, L. C.; Caffyn, A. J. M. Chem. Commun. 2005, 4479. doi:10.1039/B507752D

44. Eisenberger, P.; Kieltsch, I.; Armanino, N.; Togni, A. Chem. Commun. 2008, 1575. doi:10.1039/B801424H

45. Armanino, N.; Koller, R.; Togni, A. Organometallics 2010, 29, 1771. doi:10.1021/om100015s

46. You, S.-L.; Hou, X.-L.; Dai, L.-X.; Yu, Y.-H.; Xia, W. J. Org. Chem. 2002, 67, 4684. doi:10.1021/jo016330z

\section{License and Terms}

This is an Open Access article under the terms of the Creative Commons Attribution License

(http://creativecommons.org/licenses/by/2.0), which permits unrestricted use, distribution, and reproduction in any medium, provided the original work is properly cited.

The license is subject to the Beilstein Journal of Organic Chemistry terms and conditions:

(http://www.beilstein-journals.org/bjoc)

The definitive version of this article is the electronic one which can be found at: doi:10.3762/bjoc. 10.126 